Journal of Mathematics and Statistics 6 (4): 425-430, 2010

ISSN 1549-3644

(C) 2010 Science Publications

\title{
Variational Homotopy Perturbation Method for the Zakharove-Kuznetsov Equations
}

\author{
Mashaallah Matinfar and Maryam Ghasemi \\ Department of Mathematics, University of Mazandaran, \\ P.O. Box: 47416-95447 Babolsar, Iran
}

\begin{abstract}
Problem statement: In this research, the Variational Homotopy Perturbation Method (VHPM) which is a combination of Variational Iteration Method (VIM) and Homotopy Perturbation Method (HPM) used for the Zakharove-Kuznetsov equations (ZK-equations). Approach: These two methods are proposed by chinese researcher J.H.He. M.A.Noor improved these two methods and established the VHPM. The numerical solution of ZK-equation is of great importance dut to it's ability to model of traveling wave and nuclear fusion so, finding it's solution is very important. Results: In this study we presented an efficient and reliable treatment of the VHPM for this nonlinear Partial Differential Equations (PDEs). This method is based on Lagrange multipliers for identification of optimal value of parameters in a functional and Homotopy Perturbation Method. By applying this method we found the solution of ZK-equations with simple and reliable method and without time consuming calculations. Comparisons were made among the Variational Iteration Method (VIM), Adomian Decomposition Method (ADM) and the proposed method. Conclusion: The results revealed that the proposed method is very effective and can be used for other nonlinear problems in applied mathematics. In following sections, first we introduce the applied method, then we used that for finding the solution of our equations and finally the effectiveness and usefulness of proposed method was shown in comparison with other methods.
\end{abstract}

Key words: Variational homotopy perturbation method, Variational Iteration Method (VIM), Zakharove-Kuznetsov equation), Adomian Decomposition Method (ADM), Partial Differential Equations (PDEs), Ion Acoustic Wave (IAW)

\section{INTRODUCTION}

Traveling waves are very important because various phenomena in nature such as vibration and solitons or self-reinforcing solitary waves are described by them. So investigation of traveling wave solution plays an important role in nonlinear science. Rosenau and Hyman (1993) introduced a class of Partial Differential Equations (PDEs):

$\mathrm{K}(\mathrm{m}, \mathrm{n}): \mathrm{u}_{\mathrm{t}}+\mathrm{a}\left(\mathrm{u}^{\mathrm{m}}\right)_{\mathrm{x}}+\left(\mathrm{u}^{\mathrm{n}}\right)_{\mathrm{xxx}}=0, \mathrm{~m}>0,1<\mathrm{n} \leq 3$

which is a generalization of the Korteweg-de Vries $(\mathrm{KdV})$ equation such that describes the theory of water waves in shallow channels, for more information we can see (Saut, 1979). In Eq. 1:

$$
u_{t}=\frac{\partial u}{\partial t}, u_{x}^{m}=\frac{\partial u^{m}}{\partial x} \text { and } u_{x x x}^{n}=\frac{\partial^{3} u^{n}}{\partial x^{3}}
$$

For $\mathrm{m}=\mathrm{n}$ these are solitary waves or so-called compactons. Recently, Wazwaz (2002a; Osman and
Beech, 2004) has given the new solitary patterns for the nonlinear dispersive $K(m, n)$ equations:

$\mathrm{u}_{\mathrm{t}}-\mathrm{a}\left(\mathrm{u}^{\mathrm{m}}\right)_{\mathrm{x}}+\left(\mathrm{u}^{\mathrm{n}}\right)_{\mathrm{xxx}}=0, \mathrm{~m}>0, \mathrm{n}>0$

The new solitary wave special solutions with compact support for the nonlinear dispersive $K(m, n)$ equations:

$\mathrm{u}_{\mathrm{t}}+\mathrm{a}\left(\mathrm{u}^{\mathrm{m}}\right)_{\mathrm{x}}+\left(\mathrm{u}^{\mathrm{n}}\right)_{\mathrm{xxx}}=0, \mathrm{~m}>0, \mathrm{n}>0$

are presented by Ismail and Taha (1998) and Wazwaz (2002b) and Ganjavi et al. (2008). They use a finite difference method and a finite element method to investigate the approximate solutions of $\mathrm{K}(2,2)$ and $\mathrm{K}(3,3)$ in (1). In this study we investigate the ZKequation of the form (shortly called $\mathrm{ZK}(\mathrm{m}, \mathrm{n}, \mathrm{k})$ ):

$$
\mathrm{u}_{\mathrm{t}}+\mathrm{a}\left(\mathrm{u}^{\mathrm{m}}\right)_{\mathrm{x}}+\mathrm{b}\left(\mathrm{u}^{\mathrm{n}}\right)_{\mathrm{xxx}}+\mathrm{c}\left(\mathrm{u}^{\mathrm{k}}\right)_{\mathrm{yyx}}=0, \mathrm{mnk} \neq 0
$$

Corresponding Author: M. Matinfar, Department of Mathematics, University of Mazandaran, 
where, $\mathrm{m}, \mathrm{n}, \mathrm{k}$ are integers and $\mathrm{a}, \mathrm{b}, \mathrm{c}$ are arbitrary constants. This equation governs the behavior of weakly nonlinear ion-acoustic waves in plasma comprising cold ions and hot isothermal electrons in the present of a uniform magnetic field (Zhu, 2004); Yan (2002) Osman and Beech (2004) ZK-equation was solved by the sine-cosine and the hyperbolic tangent(tanh)-function methods. In this study, we applyied the variational homotopy perturbation method and variational iteration method to ZK-equation.

\section{MATERIALS AND METHODS}

Variational iteration and homotopy perturbation method: To illustrate the basic concepts of the VIM and HPM, at first we consider the following nonlinear differential equation:

$$
\mathrm{Lu}+\mathrm{Nu}=\mathrm{g}(\mathrm{x})
$$

Where:

$\mathrm{L}=\mathrm{A}$ linear operator

$\mathrm{N}=$ A nonlinear operator

$\mathrm{g}(\mathrm{x})=$ An inhomogeneous term

According to the VIM (He, 2000a; 2000b; He, 2002; Batiha, 2007) we can construct a correction functional as follows:

$$
\mathrm{u}_{\mathrm{n}+1}(\mathrm{x})=\mathrm{u}_{\mathrm{n}}(\mathrm{x})+\int_{0}^{\mathrm{t}} \lambda(\tau)\left\{\mathrm{Lu}_{\mathrm{n}}+\mathrm{N} \tilde{\mathrm{u}}_{\mathrm{n}}-\mathrm{g}(\tau)\right\} \mathrm{d} \tau
$$

where, $\lambda(\tau)$ is a general Lagrange multiplier. We know $\lambda(\tau)$ can be identified optimally via the variational theory, the subscript $\mathrm{n}$ denotes the nth-order approximation and $\mathrm{u}_{\mathrm{n}}$ is considered as a restricted variation i.e. $\delta \tilde{u}_{n}=0$. We know the essential idea of this method is to introduce a homotopy parameter, say $\mathrm{p}$, which takes the values from 0 to 1 . When $p=0$, the system of equations is in sufficiently simplified form, which normally admits a rather simple solution. As $p$ gradually increases to 1 , the system goes through a sequence of "deformation", the solution of each is "close" to that at the previous stage of "deformation". Eventually at $p=1$, the system takes the original form of equation and the final stage of "deformation" gives the desired solution. To illustrate the basic concept of homotopy perturbation method, consider the following nonlinear system of differential equations:

$$
\mathrm{A}(\mathrm{U})=\mathrm{f}(\mathrm{r}), \mathrm{r} \in \Omega
$$

with boundary conditions:

$$
\mathrm{B}\left(\mathrm{U}, \frac{\partial \mathrm{u}}{\partial \mathrm{n}}\right)=0, \mathrm{r} \in \Gamma
$$

Where:

$\mathrm{A}=\mathrm{A}$ differential operator

$\mathrm{B}=\mathrm{A}$ boundary operator

$\mathrm{f}(\mathrm{r})=$ A known analytic function

$\Gamma=$ The boundary of the domain $\Omega$

Generally speaking the operator A can be divided into two parts $\mathrm{L}$ and $\mathrm{N}$, where $\mathrm{L}$ is a linear and $\mathrm{N}$ is a nonlinear operator. Therefore (7) can be rewritten as follows:

$\mathrm{L}(\mathrm{U})+\mathrm{N}(\mathrm{U})-\mathrm{f}(\mathrm{r})=0$

We construct a

$\mathrm{V}(\mathrm{r}, \mathrm{p}): \Omega \times[0,1] \rightarrow \mathrm{R}^{\mathrm{n}}$, which satisfies:

$\mathrm{H}(\mathrm{V}, \mathrm{p})=(1-\mathrm{P})\left(\mathrm{L}(\mathrm{V})-\mathrm{L}\left(\mathrm{U}_{0}\right)\right]+\mathrm{p}[\mathrm{A}(\mathrm{V})-\mathrm{f}(\mathrm{r})]=0, \mathrm{p} \in$ $[0,1], r \in \Omega$

or equivalently:

$\mathrm{H}(\mathrm{V}, \mathrm{p})=\mathrm{L}(\mathrm{V})-\mathrm{L}\left(\mathrm{U}_{0}\right)+\mathrm{p} \mathrm{L}\left(\mathrm{U}_{0}\right)+\mathrm{p}[\mathrm{N}(\mathrm{V})-\mathrm{f}(\mathrm{r})]=0$

where, $\mathrm{U}_{0}$ is an initial approximation of (7). In this method, using the homotopy parameter $\mathrm{p}$, we have the following power series presentation for $\mathrm{V}$ :

$\mathrm{V}=\mathrm{V}_{0}+\mathrm{pV} 1+\mathrm{p}^{2} \mathrm{~V}_{2}+\ldots$

The approximate solution can be obtained by setting $\mathrm{p}=1$, i.e.:

$\mathrm{U}=\mathrm{U}_{0}+\mathrm{U}_{1}+\mathrm{U}_{2}+\ldots$

In following variational iteration method has been successfully used to study ZK-equation.

Variational homotopy perturbation method: To illustrate the basic idea of the VHPM, we consider the following general differential equation:

$\mathrm{Lu}+\mathrm{Nu}=\mathrm{g}(\mathrm{x})$

Where:

$\mathrm{L}=\mathrm{A}$ linear operator

$\mathrm{N}=$ A nonlinear operator

$\mathrm{g}(\mathrm{x})=$ An inhomogeneous term

According to the VIM as illustrated in previous subsection we can construct a correction functional as follows:

$$
\mathrm{u}_{\mathrm{n}+1}(\mathrm{x})=\mathrm{u}_{\mathrm{n}}(\mathrm{x})+\int_{0}^{\mathrm{t}} \lambda(\tau)\left\{\mathrm{Lu}_{\mathrm{n}}+\mathrm{N} \tilde{\mathrm{u}}_{\mathrm{n}}-\mathrm{g}(\tau)\right\} \mathrm{d} \tau
$$

where, $\lambda(\tau)$ is a general Lagrange multiplier. Now we apply the homotopy perturbation method: 
$\sum_{n=0}^{\infty} \mathrm{p}^{\mathrm{n}} \mathrm{u}_{\mathrm{n}}=\mathrm{u}_{0}(\mathrm{x})+\mathrm{p} \int_{0}^{\mathrm{t}} \lambda(\tau)\left\{\mathrm{N}\left(\sum_{\mathrm{n}=0}^{\infty} \mathrm{P}^{\mathrm{n}} \tilde{\mathrm{u}}_{\mathrm{n}}\right)\right\} \mathrm{d} \tau-\int_{0}^{\mathrm{t}} \lambda(\tau) \mathrm{g}(\tau) \mathrm{d} \tau($

which is the coupling of VIM and He's polynamials and is called the Modified Variational Iteration Method (MVIM). The comparison of like powers of $p$ gives solutions of various orders. For more information about VHPM we can see (Matinfar et al., 2010).

The VIM and VHPM for ZK-equation:

The VIM for ZK-equation: Using the VIM, for $\mathrm{n} \geq 0$ we have:

$$
\begin{aligned}
& \mathrm{u}_{\mathrm{n}+1}(\mathrm{x}, \mathrm{t})=\mathrm{u}_{\mathrm{n}}(\mathrm{x}, \mathrm{t})+\int_{0}^{\mathrm{t}} \lambda(\tau)\left\{\mathrm{u}_{\mathrm{n} \tau}(\mathrm{x}, \mathrm{y}, \tau)+\mathrm{a} \tilde{\mathrm{u}}_{\mathrm{nx}}^{\mathrm{m}}\right. \\
& (\mathrm{x}, \mathrm{y}, \tau)+\mathrm{b} \tilde{\mathrm{u}}_{\mathrm{xxxx}}^{\mathrm{n}}(\mathrm{x}, \mathrm{y}, \tau)+\mathrm{c} \tilde{\mathrm{u}}_{\mathrm{nyyx}}^{\mathrm{k}}(\mathrm{x}, \mathrm{y}, \tau) \mathrm{d} \tau
\end{aligned}
$$

where, $\tilde{u}_{\mathrm{n}}$ is considered as restricted variations, i.e., $\partial \delta \tilde{u}_{n}=0$.

To find optimal value of $\lambda(\tau)$, we have:

$$
\begin{aligned}
& \delta u_{n+1}(x, t)=\delta u_{n}(x, t)+\delta \int_{0}^{t} \lambda(\tau)\left\{u_{n \tau}(x, y, \tau)+\right. \\
& a \tilde{u}_{n x}^{m}(x, y, \tau)+b \tilde{u}_{n x x x}^{n}(x, y, \tau)+c \tilde{u}_{n y y x}^{k}(x, y, \tau) d \tau
\end{aligned}
$$

Or:

$$
\delta u_{n+1}(x, y, t)=\delta u_{n}(x, y, t)+\delta \int_{0}^{t} \lambda(\tau)\left\{u_{n \tau}\right\} d \tau
$$

which results:

$$
\begin{aligned}
& \delta u_{n+1}(x, t)=\delta u_{n}(x, y, t)+\left.\delta \lambda(\tau) u_{n}(x, y, \tau)\right|_{\tau=t} \\
& -\int_{0}^{t} \lambda(\tau) u_{n}(x, y, \tau) d \tau=0 .
\end{aligned}
$$

Therefore, the stationary conditions are obtained in the following form:

$$
1+\lambda(\tau)=\left.0\right|_{\tau=\mathrm{t}}, \lambda(\tau)=\left.0\right|_{\tau=\mathrm{t}}
$$

which results $\lambda(\tau)=-1$. Substituting this value of the Lagrange multiplier into functional (12) gives the iteration formula:

$$
\begin{aligned}
& u_{n+1}(x, y, t)=u_{n}(x, y, t)-\int_{0}^{t}\left\{u_{n \tau}(x, y, \tau)+\right. \\
& a_{n x}^{m}(x, y, \tau)+b u_{n x x x}^{n}(x, y, \tau)+c u_{n y y x}^{k}(x, y, \tau) d \tau
\end{aligned}
$$

The iteration formula (12) will give several approximations and the exact solution is obtained at the limit of the resulting successive approximations.
The VHPM for ZK-equation: In order to solve the ZK-equation with initial conditions:

$\mathrm{L}(\mathrm{u})=\mathrm{u}_{\mathrm{t}}, \mathrm{N}(\mathrm{u})=\mathrm{a}\left(\mathrm{u}^{\mathrm{m}}\right)_{\mathrm{x}}+\mathrm{b}\left(\mathrm{u}^{\mathrm{n}}\right)_{\mathrm{xxx}}+\mathrm{c}\left(\mathrm{u}^{\mathrm{k}}\right)_{\mathrm{yyx}}$

Where:

$\mathrm{L}=\mathrm{A}$ linear operator

$\mathrm{N}=$ A nonlinear operator

According to the VIM we can construct a correct functional as follows:

$$
\begin{aligned}
& \mathrm{u}_{\mathrm{n}+1}(\mathrm{x}, \mathrm{t})=\mathrm{u}_{\mathrm{n}}(\mathrm{x}, \mathrm{t})+\int_{0}^{\mathrm{t}} \lambda(\tau)\left\{\mathrm{u}_{\mathrm{nt}}(\mathrm{x}, \mathrm{y}, \tau)+\right. \\
& \mathrm{a} \tilde{u}_{\mathrm{nx}}^{\mathrm{m}}(\mathrm{x}, \mathrm{y}, \tau)+\mathrm{b} \tilde{u}_{\mathrm{nxxx}}^{\mathrm{n}}(\mathrm{x}, \mathrm{y}, \tau)+\mathrm{cu}_{\mathrm{nyyx}}^{\mathrm{k}}(\mathrm{x}, \mathrm{y}, \tau) \mathrm{d} \tau
\end{aligned}
$$

Making the above functional stationary, the Lagrange multiplier can be determined as $\lambda=-1$. Applying the VHPM, we have:

$$
\begin{aligned}
& \mathrm{u}_{0}+\mathrm{p} \mathrm{u}_{1}+\mathrm{p}^{2} \mathrm{u}_{2}+\ldots=\mathrm{f}(\mathrm{x}, \mathrm{y}) \\
& \quad-\operatorname{ap} \int_{0}^{\mathrm{t}}\left(\left(\mathrm{u}_{0}+\mathrm{pu}_{1}+\mathrm{p}^{2} \mathrm{u}_{2}+\ldots\right)^{\mathrm{m}}\right)_{\mathrm{x}} \mathrm{d} \tau \\
& \quad-\operatorname{bp} \int_{0}^{\mathrm{t}}\left(\left(\mathrm{u}_{0}+\mathrm{pu} \mathrm{u}_{1}+\mathrm{p}^{2} \mathrm{u}_{2}+\ldots\right)^{\mathrm{n}}\right)_{\mathrm{xxx}} \mathrm{d} \tau \\
& -\operatorname{cp} \int_{0}^{\mathrm{t}}\left(\left(\mathrm{u}_{0}+\mathrm{pu} \mathrm{u}_{1}+\mathrm{p}^{2} \mathrm{u}_{2}+\ldots\right)^{\mathrm{k}}\right)_{\mathrm{yyx}} \mathrm{d} \tau
\end{aligned}
$$

The comparison of like powers of $p$ gives solutions of various orders and the component which constitute $\mathrm{u}(\mathrm{x}, \mathrm{y}, \mathrm{t})$ are written like this $\mathrm{u}(\mathrm{x}, \mathrm{y}, \mathrm{t})=\mathrm{u}_{0}++\mathrm{u}_{1}+\mathrm{u}_{2}$ $+\ldots$ For later numerical computation, we let the expression $\varphi_{\mathrm{n}}=\sum_{\mathrm{i}=0}^{\mathrm{n}} \mathrm{u}_{\mathrm{i}}(\mathrm{x}, \mathrm{y}, \mathrm{t})$ to denote the $\mathrm{n}$-term approximation to $\mathrm{u}(\mathrm{x}, \mathrm{y}, \mathrm{t})$.

Implementation of VIM and VHPM for ZKequation: Now we would like to choose two special equations, namely $\mathrm{ZK}(2,2,2)$ and $\mathrm{ZK}(3,3,3)$ with specific initial conditions. At first we consider the $\mathrm{ZK}(2,2,2)$ equation:

$\mathrm{u}_{\mathrm{t}}+\left(\mathrm{u}^{2}\right)_{\mathrm{x}}+\frac{1}{8}\left(\mathrm{u}^{2}\right)_{\mathrm{xxxx}}+\frac{1}{8}\left(\mathrm{u}^{2}\right)_{\mathrm{yyx}}=0$

With specific initial conditions:

$u(x, y, 0)=f(x, y)=-\frac{4}{3} \eta \cosh ^{2}(x+y)$

where, $\eta$ is an arbitrary constant. We assume $\eta=1$ and proceeding as before, by using VIM the Lagrange 
multiplier was determined as $\lambda=-1$. Based on VHPM we have:

$$
\begin{aligned}
u_{0} & +p u_{1}+p^{2} u_{2}+\ldots=f(x, y) \\
& -p \int_{0}^{t}\left(\left(u_{0}+p u_{1}+p^{2} u_{2}+\ldots\right)^{2}\right)_{x} d \tau \\
& -\frac{1}{8} p \int_{0}^{t}\left(\left(u_{0}+p u_{1}+p^{2} u_{2}+\ldots\right)^{2}\right)_{x x x} d \tau \\
& -\frac{1}{8} p \int_{0}^{t}\left(\left(u_{0}+p u_{1}+p^{2} u_{2}+\ldots\right)^{2}\right)_{y y x} d \tau
\end{aligned}
$$
have:

Comparing the coefficient of like power of $p$, we

\begin{tabular}{|c|c|c|c|}
\hline \multirow[b]{2}{*}{$\mathrm{x}$} & \multicolumn{3}{|c|}{ at $\mathrm{t}=0.001$ and $\mathrm{y}=0.1$} \\
\hline & VHPM & VIM & $\mathrm{ADM}$ \\
\hline 0.1 & -1.4664 & -1.4664 & -1.3868 \\
\hline 0.2 & -1.4664 & -1.4664 & -1.4561 \\
\hline 0.3 & -1.4664 & -1.4664 & -1.5571 \\
\hline 0.4 & -1.7170 & -1.7170 & -1.6938 \\
\hline 0.5 & -1.9058 & -1.9058 & -1.8718 \\
\hline \multirow[b]{2}{*}{$\mathrm{x}$} & \multicolumn{3}{|c|}{ at $\mathrm{t}=0.001$ and $\mathrm{y}=0.1$} \\
\hline & VHPM & VIM & $\mathrm{ADM}$ \\
\hline 0.1 & 0.0496 & 0.1496 & 0.0498 \\
\hline 0.2 & 0.0746 & 0.1746 & 0.1748 \\
\hline 0.3 & 0.0997 & 0.0997 & 0.0998 \\
\hline 0.4 & 0.1247 & 0.1247 & 0.1249 \\
\hline 0.5 & 0.1498 & 0.1498 & 0.1500 \\
\hline
\end{tabular}

$$
\begin{aligned}
& \mathrm{p}^{0}: \mathrm{u}_{0}(\mathrm{x}, \mathrm{y}, \mathrm{t})=-\frac{4}{3} \cosh ^{2}(\mathrm{x}+\mathrm{y}) \\
& \mathrm{p}^{1}: \mathrm{u}_{1}(\mathrm{x}, \mathrm{y}, \mathrm{t})=-\int_{0}^{\mathrm{t}}\left(\mathrm{u}_{0}^{2}\right)_{\mathrm{x}} \mathrm{d} \tau \\
& -\frac{1}{8} \int_{0}^{t}\left(u_{0}^{2}\right)_{x x x} d \tau-\frac{1}{8} \int_{0}^{t}\left(u_{0}^{2}\right)_{y y x} d \tau \\
& =\left(-\frac{224}{9} \cosh ^{3}(x+y) \sinh (x+y)\right. \\
& \left.-\frac{32}{3} \cosh (\mathrm{x}+\mathrm{y}) \sinh ^{3}(\mathrm{x}+\mathrm{y})\right) \mathrm{t} \\
& =\left(-\frac{5056}{27} \cosh ^{6}(\mathrm{x}+\mathrm{y})-\frac{46784}{27}\right. \\
& \sinh ^{2}(x+y) \cosh ^{4}(x+y) \\
& =\left(-\frac{5056}{27} \cosh ^{6}(x+y)-\frac{46784}{27}\right. \\
& \sinh ^{2}(x+y) \cosh ^{4}(x+y) \\
& \mathrm{p}^{2}: \mathrm{u}_{2}(\mathrm{x}, \mathrm{y}, \mathrm{t})=-\int_{0}^{\mathrm{t}}\left(2 \mathrm{u}_{0} \mathrm{u}_{1}\right)_{\mathrm{x}} \mathrm{d} \tau-\frac{1}{8} \\
& \int_{0}^{t}\left(2 u_{0} u_{1}\right)_{x x x} d \tau-\frac{1}{8} \int_{0}^{t}\left(2 u_{0} u_{1}\right)_{y y x} d \tau \\
& -\frac{8128}{9} \sinh ^{4}(x+y) \cosh ^{2}(x+y) \\
& \left.-\frac{64}{3} \sinh ^{6}(\mathrm{x}+\mathrm{y})\right) \mathrm{t}^{2} \\
& \mathrm{p}^{3}: \mathrm{u}_{3}(\mathrm{x}, \mathrm{y}, \mathrm{t})=-\int_{0}^{\mathrm{t}}\left(2 \mathrm{u}_{0} \mathrm{u}_{2}+\mathrm{u}_{1}^{2}\right)_{\mathrm{x}} \mathrm{d} \tau-\frac{1}{8} \\
& \int_{0}^{t}\left(2 u_{0} u_{2}+u_{1}^{2}\right)_{x x x} d \tau-\frac{1}{8} \int_{0}^{t}\left(2 u_{0} u_{2}+u_{1}^{2}\right)_{y y x} d \tau \\
& =\left(-\frac{12869632}{243} \sinh (x+y) \cosh ^{7}(x+y)\right. \\
& -\frac{6025216}{27} \sinh ^{3}(\mathrm{x}+\mathrm{y}) \cosh ^{5}(\mathrm{x}+\mathrm{y}) \\
& -\frac{9551872}{81} \sinh ^{5}(x+y) \cosh ^{3}(x+y) \\
& \left.-\frac{192512}{21} \sinh ^{7}(x+y) \cosh (x+y)\right) t^{3}
\end{aligned}
$$

Table 1: The numerical results for $\phi_{3 \mathrm{VHPM}}, \mathrm{u}_{3 \mathrm{VM}}$ and ADM

Thus the components which constitute $\mathrm{u}(\mathrm{x}, \mathrm{y}, \mathrm{t})$ are written like this:

$$
\begin{aligned}
& u(x, y, t)=-\frac{4}{3} \cosh ^{2}(x+y)+ \\
& \left(-\frac{224}{9} \cosh ^{3}(x+y) \sinh (x+y)\right. \\
& \left.-\frac{32}{3} \cosh (x+y) \sinh ^{3}(x+y)\right) t \\
& +\left(-\frac{5056}{27} \cosh ^{6}(x+y)\right. \\
& -\frac{46784}{27} \sinh ^{2}(x+y) \cosh ^{4}(x+y) \\
& -\frac{8128}{9} \sinh ^{4}(x+y) \cosh ^{2}(x+y) \\
& \left.-\frac{64}{3} \sinh ^{6}(x+y)\right) t^{2} \\
& +\left(-\frac{12869632}{243} \sinh ^{2}(x+y) \cosh ^{7}(x+y)\right. \\
& -\frac{6025216}{27} \sinh ^{3}(x+y) \cosh ^{5}(x+y) \\
& -\frac{9551872}{81} \sinh ^{5}(x+y) \cosh ^{3}(x+y) \\
& -\frac{192512}{21} \sinh ^{7}(x+y) \cosh ^{(x+y)) t^{3}}
\end{aligned}
$$

We now consider the $\mathrm{ZK}(3,3,3)$ equation:

$u_{t}+\left(u^{3}\right)_{x}+2\left(u^{3}\right)_{x x x x}+2\left(u^{3}\right)_{y y x}=0$

with specific initial conditions $\mathrm{u}(\mathrm{x}, \mathrm{y}, 0)=\mathrm{f}(\mathrm{x}, \mathrm{y})=1.5$ $\eta \sinh ((x+y) / 6)$, as mentioned in previous example we assume $\eta=1$. By using VIM the Lagrange multiplier is determined as $\lambda=-1$. Applying VHPM and substituting the series in nonlinear section of this equation we have: 
$\left.\mathrm{p}^{0}: \mathrm{u}_{0}(\mathrm{x}, \mathrm{y}, \mathrm{t})=1.5 \sinh ^{2}(\mathrm{x}+\mathrm{y}) / 6\right)$,

$\mathrm{p}^{1}: \mathrm{u}_{1}(\mathrm{x}, \mathrm{y}, \mathrm{t})=-\int_{0}^{\mathrm{t}}\left(\mathrm{u}_{0}^{3}\right)_{\mathrm{x}} \mathrm{d} \tau$

$-2 \int_{0}^{t}\left(u_{0}^{3}\right)_{x x x} d \tau-2 \int_{0}^{t}\left(u_{0}^{3}\right)_{y y x} d \tau$

$=\left(-3 \cosh ^{2}(x+y) / 6\right) \cosh ((x+y) / 6)$

$-\frac{3}{8} \cosh ^{3}((x+y) / 6) t$

$\mathrm{p}^{2}: \mathrm{u}_{2}(\mathrm{x}, \mathrm{y}, \mathrm{t})=-\int_{0}^{\mathrm{t}}\left(3 \mathrm{u}_{0}^{2} \mathrm{u}_{1}\right)_{\mathrm{x}} \mathrm{d} \tau-2$

$\int_{0}^{t}\left(3 u_{0}^{2} u_{1}\right)_{x x x} d \tau-2 \int_{0}^{t}\left(3 u_{0}^{2} u_{1}\right)_{y y x} d \tau$

$=\left(\frac{273}{64} \sinh ^{5}((x+y) / 6)+\frac{1641}{64} \sinh ^{2}((x+y) / 6)\right.$

$\cosh ^{2}((x+y) / 6)$

$\left.+\frac{381}{64} \sinh ((x+y) / 6) \cosh ^{4}((x+y) / 6)\right) t^{2}$

$\mathrm{p}^{3}: \mathrm{u}_{3}(\mathrm{x}, \mathrm{y}, \mathrm{t})=-\int_{0}^{\mathrm{t}}\left(3 \mathrm{u}_{0} \mathrm{u}+\mathrm{u}_{1}^{2}\right)_{\mathrm{x}} \mathrm{d} \tau-\frac{1}{8}$

$\int_{0}^{t}\left(2 u_{0} u_{2}+u_{1}^{2}\right)_{x x x} d \tau-2 \int_{0}^{t}\left(3 u_{0} u_{1}^{2}+3 u_{0}^{2} u_{2}\right)_{x x x} d \tau$

$=\left(-\frac{39851}{256} \sinh ^{6}((x+y) / 6) \cosh (x+y) / 6\right)$

$-\frac{114915}{256} \sinh ^{4}((x+y) / 6) \cosh ^{3}((x+y) / 6)$

$-\frac{16455}{128} \sinh ^{2}((\mathrm{x}+\mathrm{y}) / 6) \cosh ^{5}((\mathrm{x}+\mathrm{y}) / 6)$

$\left.-\frac{505}{256} \cosh ^{7}((x+y) / 6)\right) t^{3}$

and proceeding as before $\mathrm{u}(\mathrm{x}, \mathrm{y}, \mathrm{t})=\mathrm{u}_{0}+\mathrm{u}_{1}+\mathrm{u}_{2}+\ldots$.

\section{RESULTS}

To illustrate the accuracy of applied method comparison of the VHPM with other approaches is presented in Table 1 and 2 and Fig. 1-4.

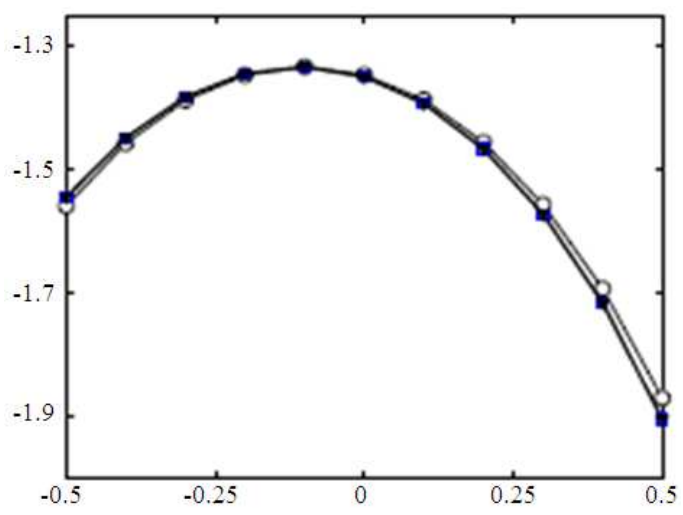

Fig. 1:Comparison between VHPM, VIM and ADM at $\mathrm{y}=0.1$ and $\mathrm{t}=0.0010$
By studding Fig. 1 and 2 and Table 1 we find that there is excellent agreement with our method and VIM and ADM for ZK(2,2,2) (Ganjavi et al., 2008; Inc, 2008).

As we can see in Fig. 3 and 4 and Table 2 the obtained results for $\mathrm{ZK}(3,3,3)$ by using the VHPM is very close to the results that were obtained by VIM and ADM (Ganjavi et al., 2008; Inc, 2008).

This is important that one application of $\mathrm{ZK}$ equation is describing Ion Acoustic Wave (IAW) in inertial fusion and Tokamak. As we know interaction time in bullet and creating high density plasma in Tokamak is short, so we plot our figures and set our tables in short time (Miyamoto, 2005; Osman et al., 2005).

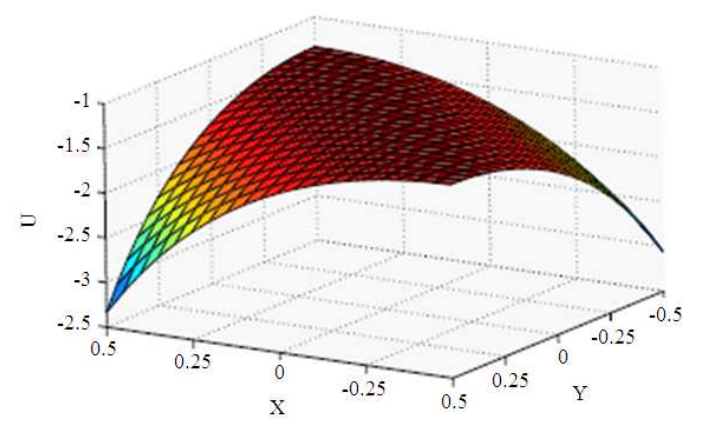

Fig. 2: VHPM at $\mathrm{t}=0.001$

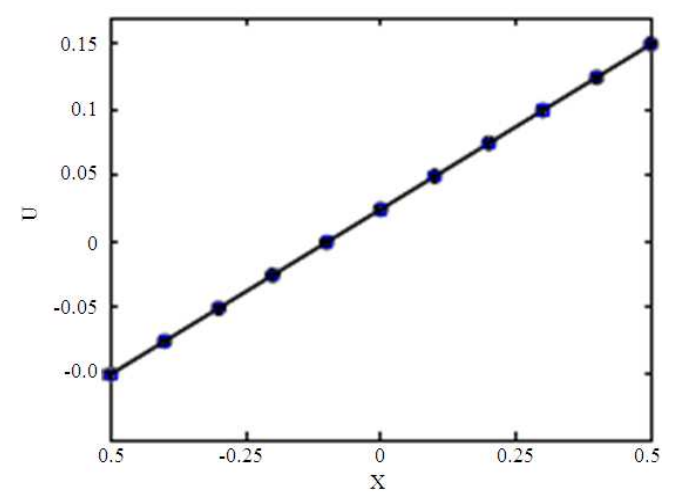

Fig. 3: Comparison between VHPM, VIM and ADM at $\mathrm{y}=0.1$ and $\mathrm{t}=0.001$

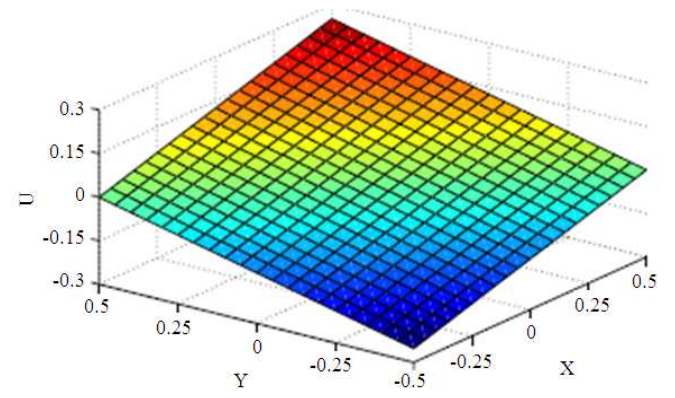

Fig. 4: VHPM at $\mathrm{t}=0.001$ 


\section{DISCUSSION}

In this study we carefully applied the VHPM to solve the ZK-equations. In the VHPM we should ignore the time derivative section so, it has less amount of computation in comparison with VIM and ADM. By studying the examples it is clear that there is no need to calculate difficult integration that exists in VIM so, we can use this method in solving other nonlinear or linear problems without time consuming computations.

\section{CONCLUSION}

In this Letter, Variational homotopy perturbation method is proposed for solving the ZK-equation. By studying the tables and figures it is clear that the small amount of computation is required compared to other methods such as VIM and ADM. In our study we use the MATLAB software to calculate the series obtained from the VIM and VHPM.

\section{REFERENCES}

Batiha, K., 2007. Approximate Analytical Solutions For Time-Dependent Emden-Fowler-Type Equations By Variational Iteration Method. Am. J. Applied Sci., 4: 439-443. DOI: 10.3844/.2007.439.443

Ganjavi, B., H. Mohammadi, D.D. Ganji and A. Barari, 2008. Homotopy perturbation method and variational iteration method for solving ZakharovKuznetsov equation. Am. J. Applied Sci., 5: 811-817. ISSN: 1546-9239

He, J.H., 2000a. A coupling method of a homotopy technique and a perturbation technique for nonlinear problems. Int. J. Non. Mech., 35: 37-43. http://works.bepress.com/ji_huan_he/13

He, J.H., 2000b. Variational iteration method for autonomous ordinary differential systems. Applied Math. Comput., 114: 3115-3123. DOI: 10.1016/S0096-3003(99)00104-6

He, J.H., 2002. Homotopy perturbation method: A new nonlinear analytical technique. Applied Math. Comput., 135: 73-79. DOI: 10.1016/S00963003(01)00312-5
Inc, M., 2008. Exact solutions with solitary patterns for the Zakharov-Kuznetsov equations with fully nonlinear dispersion. Chao. Soli. Frac., 33: 1783-1790. DOI: 10.1016/j.chaos.2006.03.017

Ismail, M.S. and T.R. Taha, 1998. A numerical study of Compactions. Math. Comput. Simul., 47: 519-550.

Matinfar, M., M. Mahdavi and Z. Raeisi, 2010. The variational homotopy perturbation method for solving analytic treatment of the linear and nonlinear ordinary differential equations. J. Applied Math. Inform., 28: 845-862.

Miyamoto, K., 2005. Plasma Physics and Controlled Nuclear Fusion. 1st Edn., Springer, New York, pp: 371. ISBN: 3-540-24217-1

Osman, F. and R. Beech, 2004. Programming of the Generalised Nonlinear Paraxial Equation for the Formation of Solitons with Mathematica. Am. J. Applied Sci., 1: 100-106. DOI: 10.3844/.2004.100.106

Osman. F, P. Evans, P. Toups and H. Hora, 2005. Laser Interaction and Related Plasma Phenomena. Am. J. Applied Sci., 2: 403-409. http://findarticles.com/p/articles/mi_7109/is_1_2/ai nn28319063/

Rosenau, D. and J.M. Hyman, 1993. Compactons Solitons with finite wavelengths, Phys. Rev. Lett., 70: 564-567.

Saut, J.C., 1979. Quelques gnralisations de l'quation de Korteweg-de Vries. J. Differential Eq., 33: 320-335.

Wazwaz, A.M., 2002a. Exact special solutions with solitary patterns for the nonlinear dispersive k(m,n)equations. Chao. Soli. Frac., 13: 161-170. DOI: 10.1016/S0960-0779(00)00248-4

Wazwaz, A.M., 2002b. New solitary-wave special solution with compact support for the nonlinear dispersive $k(m, n)$ equations. Chao. Soli. Frac., 13: 321-330. DOI: 10.1016/S0960-0779(00)00249-6

Yan, Z., 2002. New families of solitons with compact support for Boussinesq-Like B(m,n) equations with fully nonlinear dispersion. Chao. Soli. Frac., 14: 1151-1158. DOI: 10.1016/S0960-0779(02)00062-0

Zhu, Y., 2004. Exact special solutions with solitary patterns for Boussinesq-Like $B(m, n)$ equations with fully nonlinear dispersion. Chao. Soli. Frac., 22: 213-220. DOI: 10.1016/j.chaos.2003.12.101 